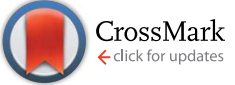

Cite this: RSC Adv., 2017, 7, 6636
Received 9th November 2016 Accepted 7th January 2017

DOI: $10.1039 / c 6 r a 26542 a$

www.rsc.org/advances

\section{Synthesis of human hair fiber-impregnated chitosan beads functionalized with citric acid for the adsorption of lysozyme}

\begin{abstract}
Xiaohui $\mathrm{Xu}^{\mathrm{a}}{ }^{\mathrm{B} \text { Bo Bai, }}{ }^{\text {b }}{ }^{\mathrm{b}}$ Honglun Wang ${ }^{\mathrm{b}}$ and Yourui Suo ${ }^{\mathrm{b}}$
Chitosan materials have been applied widely in protein separation and purification processes, however, pure chitosan materials generally suffer from inadequate mechanical properties and low densities of active adsorption sites, thereby leading to short service lives, limited actual re-usage counts and unexpected re-absorption capacities as adsorbents. Herein, a novel CA-CS/HHF composite was firstly constructed by impregnating human hair fiber into a CS matrix and then functionalized with citric acid. The structures and morphologies of the thus-produced composites were characterized by FTIR and SEM, respectively. A mechanical stability test showed that the impregnation of HHF into the chitosan matrix could effectively enhance the mechanical stability of the CA-CS/HHF beads in comparison with pure chitosan spheres. The adsorption of proteins and a protein mixture revealed that the product could adsorb positively charged proteins, as ascertained by the method of sodium dodecyl sulfate polyacrylamide gel electrophoresis. The maximum value for LYZ adsorption on the CA-CS/HHF composite was $42.1 \mathrm{mg} \mathrm{g}^{-1}$ with a fast equilibrium time of $3 \mathrm{~h}$. Moreover, the resultant product exhibited good reversibility with respect to lysozyme. This simple and intriguing approach characterized by both environmental conservation and waste recycling strongly extends any future utilization of human hair fiber, and the resultant CA-CS/HHF can potentially be truly applied for the quick and effective adsorption of positively charged lysozyme.
\end{abstract}

\section{Introduction}

In recent years, using absorptive approaches for the highly efficient purification of proteins has found widespread utilization in biochips and biosensors, ${ }^{1}$ foodstuffs,${ }^{2}$ cosmetics,${ }^{3}$ and the biomedical and pharmaceutical industries. ${ }^{4,5}$ For example, a great number of protein carrying adsorbents with remarkable selectivities, including nanosilica, ${ }^{6} \mathrm{TiO}_{2}$ nanotubes, ${ }^{7}$ graphene, ${ }^{8}$ and carbon nanotubes, ${ }^{9}$ have been developed. It has been verified that these adsorbents possess high selectivities and binding capacities, but generally suffer from high production costs and difficulties in their preparation and separation. ${ }^{10}$ Alternatively, chitosan (CS), the second most abundant natural polymer after cellulose, has been proposed for applications in protein separation and purification processes because of its high affinity to proteins, good biocompatibility, and antibacterial and hydrophilic properties. ${ }^{11-13}$ Several chitosan-based adsorbents including chitosan nanoparticles, ${ }^{14}$ chitosan films ${ }^{15}$ chitosan microspheres,${ }^{16}$ a magnetite/graphene oxide/

${ }^{a}$ College of Environmental Science and Engineering, Chang'an University, Xi'an, 710054, P. R. China

${ }^{b}$ State Key Laboratory of Plateau Ecology and Agriculture (Qinghai University) Xining, 810001, P. R. China. E-mail: baibochina@163.com; Fax: +86 29 82339961; Tel: +86 2982339052 chitosan composite, ${ }^{17}$ and chitosan derivative beads ${ }^{18}$ have already been explored for protein adsorption applications. Chitosan beads are more extensively used than the film or powdered forms owing to their easy fabrication and scale-up, controllable particle size, excellent dispersion stability, and simple recovery process. ${ }^{19}$ Regardless of such interesting features, it has been found unfortunately that pure CS materials generally suffer from inadequate mechanical properties, thereby leading to short service lives, limited actual re-usage counts and unexpected re-absorption capacities as adsorbents. ${ }^{20}$ To address the abovementioned shortcomings, the impregnation of natural fibers, like silk fibers, ${ }^{21}$ rice straw fibers, ${ }^{22}$ cellulose fiber ${ }^{23}$ and carbon fiber, ${ }^{24}$ into the CS matrix has been shown to act as an efficient way to achieve desirable chitosan beads with highly strengthened mechanical properties.

Human hair fiber (HHF), a nanocomposite biological fiber with a diameter of about $80 \mu \mathrm{m}$, is a material considered useless in most societies and therefore the common management options for human hair include dumping or burning as waste, which are characterized by serious resource waste and significant environmental pollution. ${ }^{25,26}$ The chief constituent of human hair is mainly keratin protein, which comprises about $65-95 \%$, whereas of the other components about $32 \%$ is water and lipid pigments. ${ }^{27}$ The existence of cortex keratin endows 
HHF with surprising strength and the rupture load of a healthy hair fiber ranges from 50 to $100 \mathrm{~g} .{ }^{25}$ By virtue of its high tensile strength, HHF has been used for reinforcing clay-based constructions, and it has been verified that the addition of hair significantly enhances the structural strength and prolongs the life of these clay structures. ${ }^{28}$ More importantly, as a potential material resource, human hair possesses other supplementary advantages including being completely biodegradable, clearly renewable, naturally abundant and available in every locality. Considering these attractive characteristics, HHF holds great promise as a reinforcing agent to improve the mechanical properties of brittle chitosan bead materials, yet this has never been reported before.

Conventionally, neat chitosan materials usually do not have high adsorption capacities or efficiencies as a result of their relatively small surface areas and low levels of active anchoring sites. To improve their protein adsorption performance, further surface functionalization or modification of the chitosan materials is urgently needed. All in all, the fundamental protocol for the modification of chitosan can be attributed to hydroxyl and amidogen groups inherited from chitosan, which have provided a versatile platform for secondary reactions with other desired molecules. The main goals of such modifications of chitosan were mainly focused on the enhancement of its protein binding capacity. For instance, Bayramoğlu et al. grafted poly (methacrylic acid) onto chitosan beads using grafting copolymerization initiated by ammonium persulfate under a nitrogen atmosphere, and the resultant products possessed relatively high adsorption capacities toward lysozyme. ${ }^{29}$ Hua et al. modified chitosan with ethylenediaminetetraacetic acid and the obtained materials could specifically bind his-tagged proteins. $^{30}$ Sun et al. synthesized carboxymethyl chitosan magnetic nanoparticles by a chemical coprecipitation method and then treated these with various ion solutions for lysozyme separation and purification. ${ }^{31}$ Recently, Ding et al. have demonstrated another fascinating protein adsorbent by in situ functionalizing electrospun ethylene-vinyl alcohol nanofibrous membranes with critic acid (CA). ${ }^{32}$ It has been verified that the CA performs well as a natural grafting agent since it can introduce substantial carboxyl functional groups to the $\mathrm{CS} / \mathrm{HHF}$ matrix, significantly improving the availability of active adsorption sites. Simultaneously, the relatively long carbon chains of CA can also serve as spacer arms to weaken the steric hindrance between the adsorption sites and target molecules, further facilitating the protein binding process. ${ }^{33}$ Such modification methods render chitosan adsorbents with improved adsorption performance, and consequently provide a new kind of functional material for the fast, effective, and low cost production of various highly purified protein products.

Thus, in the present paper, novel CA-CS/HHF composite beads were fabricated by impregnating HHF into a CS matrix as a reinforcing filler through an instantaneous gelation method and subsequent heat treatment to graft citric acid molecules under mild conditions. Benefiting from the tough and inexpensive HHF filler and the abundant carboxyl groups of CA, the resultant CA-CS/HHF composite beads exhibit the integrated properties of a high number of active sites and robust mechanical strength. Such fantastic advantages endow the asprepared CA-CS/HHF with brilliant adsorption performance, including efficient separation, a high adsorptivity towards lysozyme (LYZ), a fast adsorption equilibrium, and good reversibility, implying that this material could potentially be truly used in protein adsorption fields.

\section{Experimental}

\subsection{Materials}

Human hair fibers (HHF) were collected from a barbershop (Shaanxi, China). Chitosan (CS) with a molecular weight of 200000 and an $88 \%$ degree of deacetylation was supplied by Tianjin Chemical Reagent Factory (Tianjin, China). Before use, the raw human hair was cleaned three times with distilled water, dried in an oven at $60{ }^{\circ} \mathrm{C}$ for $24 \mathrm{~h}$, and finally cut into pieces with lengths of less than $1 \mathrm{~mm}$. Citric acid, sodium hydroxide, acetic acid and acetone were supplied by Tianjin Chemical Reagent Factory (Tianjin, China). All the chemicals used in the present study were of reagent grade and were used without further purification.

\subsection{Preparation of the CA-CS/HHF composite beads}

Typically, $0.2 \mathrm{~g}$ of chitosan was dissolved in $10 \mathrm{~mL}$ of $2 \%(\mathrm{v} / \mathrm{v})$ acetic acid solution, then a specific amount of human hair fiber $(0-50 \%)$ was immersed in the solution. After magnetic stirring at $250 \mathrm{rpm}$ for $20 \mathrm{~min}$ at room temperature, a homogenously dispersed chitosan-HHF dispersion was achieved and dropwise added into a precipitation bath containing a $5 \mathrm{wt} \%$ $\mathrm{NaOH}$ solution through a $0.8 \mathrm{~mm}$ gauge syringe needle, and subsequently chitosan/human hair fiber (CS/HHF) beads were obtained. Blank CS beads were obtained by a similar preparation process without adding HHF. The beads were soaked in deionized water for $24 \mathrm{~h}$ and then rinsed with deionized water five times. The immobilization of citric acid on the CS/HHF intermediates' surfaces was performed according to the method reported in previous work with some modification. ${ }^{34}$ The prepared CS/HHF beads $(1 \mathrm{~g})$ were dispersed in methanol solutions with various citric acid concentrations $(0,0.1,0.2,0.3$, $0.4,0.5$ and $0.6 \mathrm{~mol} \mathrm{~L}^{-1}$ ) at $50{ }^{\circ} \mathrm{C}$ for a certain time. Next, to completely eliminate excess citric acid, the beads were washed with deionized water and the residues were retained in an aqueous environment for future use.

\subsection{Testing mechanical performance}

Compression strength testing is an easily performed and visualized way to evaluate the mechanical strength of a bead. The prepared samples were analyzed by an Instron 3345 materials testing machine with a $10 \mathrm{~N}$ force transducer. A wet bead was placed onto a flat platform and compressed to a deformation of $40 \%$ by a flat-tip probe at a speed of $0.5 \mathrm{~mm} \mathrm{~min}^{-1}$. Five beads from each sample were compressed in order to provide statistically representative measurements. Applied force $(F)$ versus displacement $(H)$ data was generated from the compression measurements, and was employed to determine the Young's modulus $(E)$ according to the Hertz model. ${ }^{35}$ 


$$
F=\frac{4 R^{1 / 2}}{3} \frac{E}{1-v^{2}}\left(\frac{H}{2}\right)^{3 / 2}
$$

where $R$ is the radius of a bead, and $v$ (taken as 0.5 ) is the Poisson ratio. ${ }^{36}$

\subsection{Determination of carboxyl content}

The carboxyl content of the CA-CS/HHF composite beads was determined by using an acid-base titration method reported by Salam. ${ }^{37} 1.0 \mathrm{~g}$ of the obtained sample was firstly dissolved in excess $0.1 \mathrm{~mol} \mathrm{~L}^{-1} \mathrm{NaOH}$ ( $\mathrm{pH} 12.5$ ) for $1 \mathrm{~h}$, and then $0.1 \mathrm{~mol} \mathrm{~L}^{-1}$ $\mathrm{HCl}$ was added to the mixture using phenolphthalein as an indicator. The carboxyl content (meq./100 g) in milliequivalents of acidity per $100 \mathrm{~g}$ is obtained by:

$$
\text { Carboxyl content }=\frac{\left(V_{\mathrm{b}}-V_{\mathrm{a}}\right)}{M} \times C_{\mathrm{HCl}} \times 100
$$

where $V_{\mathrm{a}}$ and $V_{\mathrm{b}}(\mathrm{mL})$ represent the volume of $\mathrm{HCl}$ used to titrate in the presence and in the absence of the product, respectively. $C_{\mathrm{HCl}}$ is the normality of the used $\mathrm{HCl}$, and $M(\mathrm{~g})$ is the mass of the dry specimen.

\subsection{Testing adsorption performance}

To investigate the static adsorption performance of the CA-CS/ HHF composite beads toward different types of separate proteins, $0.5 \mathrm{~g}$ of freeze-dried samples were soaked in $100 \mathrm{~mL}$ of protein solution $\left(1 \mathrm{~g} \mathrm{~L}^{-1}\right)$ for a certain time; subsequently the absorbance intensity change was detected using a UV-visible spectrophotometer to determine the protein concentration. The amount of adsorbed protein $q_{t}\left(\mathrm{mg} \mathrm{g}^{-1}\right)$ at various times $(t)$ was calculated by the following (eqn (3)):

$$
q_{t}=\frac{\left(C_{0}-C_{t}\right) V}{m}
$$

where $m$ is the amount of sample $(\mathrm{g}), V$ is the volume of the protein solution (L), and $C_{0}$ and $C_{\mathrm{t}}$ are the initial concentration of the protein solution and its concentration at time $t\left(\mathrm{~g} \mathrm{~L}^{-1}\right)$. Additionally, the method of sodium dodecyl sulfate polyacrylamide gel electrophoresis (SDS-PAGE) ${ }^{38}$ was employed to analyze the selective adsorption ability of CA-CS/HHF composite beads toward a protein mixture (containing LYZ, bromelain, BSA, albumin, and pepsin).

To test the reversible adsorption property of the as-prepared CA-CS/HHF composite beads, consecutive adsorption-desorption experiments were conducted with $0.5 \mathrm{M} \mathrm{NaCl}$ for ten cycles. Briefly, the LYZ-loaded beads were immersed in $50 \mathrm{~mL}$ of $\mathrm{NaCl}$ solution for a period of $20 \mathrm{~min}$ to elute the adsorbed protein, then the composites were rinsed with fresh deionized water 3 times to remove the $\mathrm{NaCl}$. After that, the regenerated composite beads were dipped into the lysozyme solution to reuse for another cycle.

\subsection{Characterization}

The functional groups of the obtained products and human hair were confirmed using a Perkin Elmer FTIR System 2000 in the $600-4000 \mathrm{~cm}^{-1}$ range at a resolution of $4 \mathrm{~cm}^{-1}$ using the $\mathrm{KBr}$ wafer technique. A scanning electron microscope (JSM-6490LV, and $10 \mathrm{kV}$ ) was employed to observe the morphological changes of the obtained products and human hair. Before SEM analysis, the obtained beads were dried via lyophilisation and the human hair was dried at $60{ }^{\circ} \mathrm{C}$, then all the samples were coated with gold using an Emitech $\mathrm{K} 550$ Coater. The concentrations of the protein solutions were detected using a Shimadzu-18A UVvisible spectrophotometer. Mechanical stability testing was conducted by an Ultrasonic cell disrupter (KH-160TDV) with frequency $20 \mathrm{kHz}$ and power $100 \mathrm{~W}$.

\section{Results and discussion}

\subsection{Synthesis and characterization of CA-CS/HHF composite beads}

The detailed functionalization and fabrication processes of the CA-CS/HHF composite beads are schematically illustrated in Scheme 1.

According to previous reports, the incorporation of natural fibers is an effective and frequently used approach to reinforce the physico-chemical properties of a chitosan matrix. ${ }^{21-24}$ In the current study, the interactions between the HHF fillers and the chitosan matrix may include covalent and non-covalent interactions such as hydrogen bond interactions and electrostatic interactions. These can be observed during the synthesis by the apparent change of the morphology of the chitosan-HHF dispersion from a suspension to beads when drops of the mixture were neutralized and gelated in an alkaline solution. In other words, the HHF filler has been successfully buried in the CS matrix, and millimetric CS/HHF hybrid beads with free $-\mathrm{NH}_{2}$ and $-\mathrm{OH}$ groups were constructed by the dropping and $\mathrm{pH}$ precipitation method. These groups are of great importance since they can afford secondary reactions with many citric acid molecules. In the subsequent citric acid immobilization process, lots of free CA molecules were anchored through hydrogen bond linkages on the surfaces of the CS/HHF beads, which contain numerous hydroxyl $(-\mathrm{OH})$ and amino groups $\left(-\mathrm{NH}_{2}\right)$. Under the subsequent heating conditions at $50{ }^{\circ} \mathrm{C}$, two adjacent carboxylic acid groups of CA were easily dehydrated and lost one water molecule to yield a cyclic anhydride. ${ }^{39}$ The reactive anhydrides subsequently reacted with other hydroxyl or amino groups on the chitosan surface. Hereby, the overall surfaces of the CS/HHF beads were decorated with lots of citric acid molecules and numerous carboxylic groups were introduced for binding proteins.

From the above analysis, it can be supposed that the chitosan, citric acid and human hair fiber have made their own extraordinarily important contributions to the formation of the CA-CS/HHF hybrid beads. Namely, (1) for the chitosan component, the native entanglement or crosslinking properties of the chitosan polymer chains help the discrete HHFs unite together, forming uniform spherical structures, which greatly simplifies the isolation procedure and speeds up the assay process. Also, the inherent and ample hydroxyl and amidogen groups on the CS substrates can be used for further derivatization, making the grafting reaction of the CA molecules occur facilely on the surface of CS/HHF. (2) As with classical fillers, the utilization of 


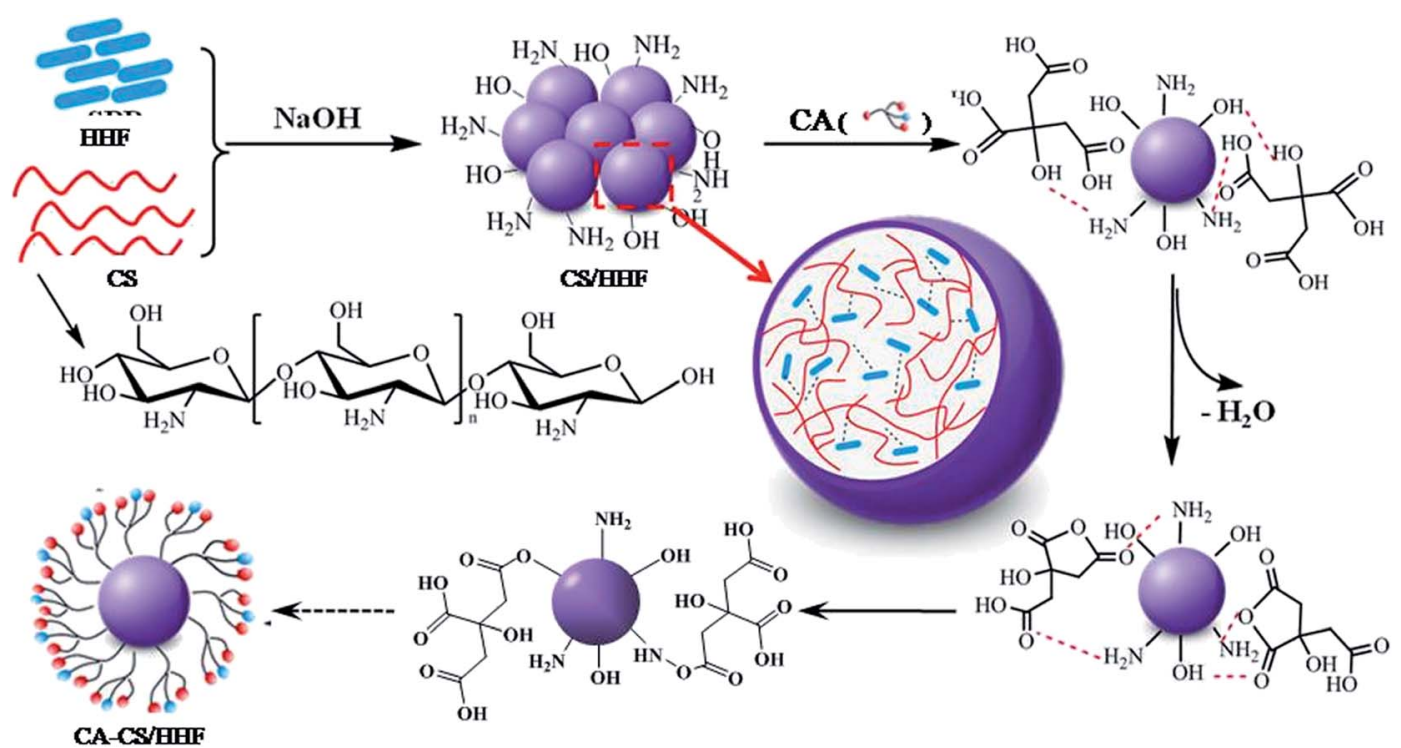

Scheme 1 Proposed mechanism for the formation of CA-CS/HHF hybrid beads.

HHF as an inner skeleton can also strengthen the mechanical stability of CA-CS/HHF composite beads. Of course, it is obvious that the partial replacement of the internal parts of the CS beads with HHF fillers will have avoided unnecessary waste of the chitosan resource and reduced the production costs of these absorbent materials greatly. (3) The CA molecules used as modifiers in this research are natural and environmentally friendly. They offer a large number of active sites (carboxyl groups) for binding protein molecules and decrease the steric hindrance between the adsorption sites, and consequently help the CA-CS/HHF composite beads capture proteins easily, which significantly improves the adsorption performance of CA-CS/ HHF composite beads. From these points of view, this intriguing and economical strategy opens a suitable route to prepare a protein adsorbent with an improved absorption capacity and mechanical strength by using the abundance, biodegradability and renewability traits of CS and HHF.

To analyse structure and surface composition changes, the valuable and well established testing technique of FTIR spectroscopy was employed and the spectra of the intermediates and the final product are exhibited in Fig. 1.

For HHF, the broad and strong peak around $3425 \mathrm{~cm}^{-1}$ corresponds to $-\mathrm{OH}$ and $-\mathrm{NH}$ stretching vibrations, and the medium absorption peak at $2924 \mathrm{~cm}^{-1}$ represents the $-\mathrm{CH}$ stretching of the methylene groups in human hair. The absorption bands at 1644, 1544, 1157 and $1070 \mathrm{~cm}^{-1}$ are assigned to $\mathrm{C}=\mathrm{O}$ stretching (amide $\mathrm{I}$ ), $-\mathrm{NH}$ bending (amide II), antisymmetric stretching vibrations of $\mathrm{C}-\mathrm{O}-\mathrm{C}$ bridges, and skeletal vibrations involving $\mathrm{C}-\mathrm{O}$ bonds stretching separately, which are the characteristic absorption peaks of human hair. ${ }^{40}$ As for chitosan, the peak at $3425 \mathrm{~cm}^{-1}$ is attributed to the stretching of free amine $\left(-\mathrm{NH}_{2}\right)$ and hydroxyl $(-\mathrm{OH})$ functional groups in the ring of CS. The peaks at 1544 and $1424 \mathrm{~cm}^{-1}$ are related to $-\mathrm{NH}_{2}$ and $-\mathrm{OH}$ bending vibrations respectively, suggesting the existence of amido and hydroxyl groups. In the IR spectrum of the CS/HHF intermediate, the above characteristic absorption peaks belonging to HHF and CS were almost retained. The above results provide preliminary evidence that HHF and chitosan were intertwined and that together they formed a stable CS/HHF hybrid bead, which can be further confirmed by the subsequent scanning electron microscopy (SEM) step. Following the subsequent reaction between the CS/ HHF beads and CA, the final product shows some changes in its absorption peaks. For instance, the absorption band near 1544 $\mathrm{cm}^{-1}$, corresponding to the bending vibrations of $-\mathrm{NH}_{2}$ in the CS ring, vanished in the CA-CS/HHF spectra, suggesting that some of the amine groups in the CS/HHF beads had already reacted with the $-\mathrm{COOH}$ groups of CA. Moreover, it can be distinctly observed that two intense peaks appear at 1257 and $920 \mathrm{~cm}^{-1}$ in (d) which are ascribed to the $\mathrm{C}=\mathrm{O}$ stretching

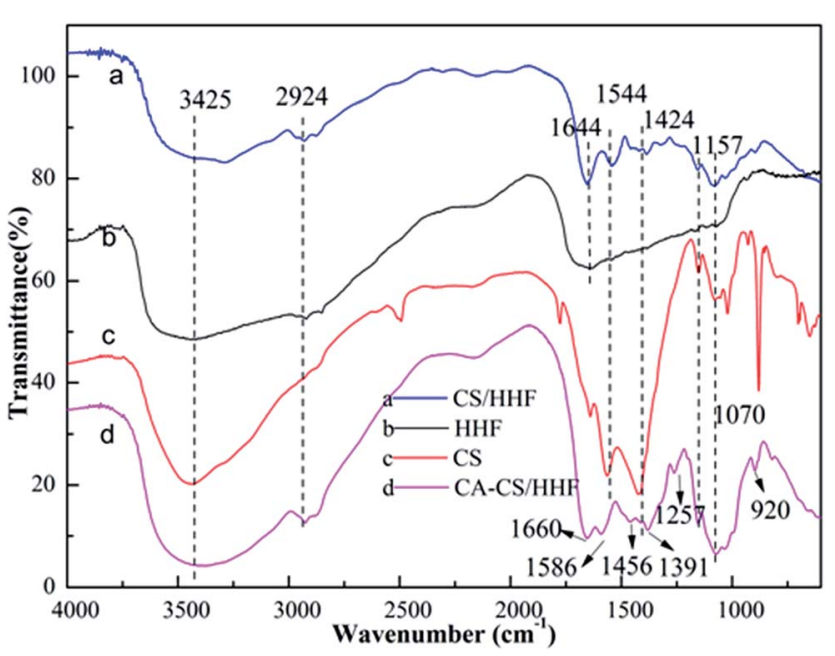

Fig. 1 FTIR spectra of HHF fillers (b), chitosan (c), CS/HHF beads (a), and CA-CS/HHF composite beads (d). 
vibrations of carboxyl groups and $-\mathrm{OH}$ bending vibrations in $\mathrm{COOH}$, further demonstrating the introduction of additional carboxyl groups onto the CS/HHF surface during the modification with CA. ${ }^{41}$ Besides this, the peak at $1660 \mathrm{~cm}^{-1}$ is assigned to carboxamide, caused by the superposition of the $\mathrm{C}=\mathrm{O}$ in amide $\mathrm{I}$ and $\mathrm{C}=\mathrm{O}$ in $\mathrm{COOH}$, and the bands at 1586, 1456 and 1391 $\mathrm{cm}^{-1}$ are due to $\mathrm{C}=\mathrm{O}$ asymmetric and symmetric stretching in a carboxylate anion. ${ }^{42}$ Comparing the FT-IR spectra of CS/HHF and CA-CS/HHF suggested that the CA was anchored on the surface of the CA-CS/HHF hybrid beads.

The incorporation of HHF into the CS matrix can be further verified from photographs (Fig. 2a) and the influence of the HHF filler on the microstructure of the dried CA-CS/HHF beads is observed in the SEM images (Fig. 2b-d). Fig. 2a shows the appearance of prepared wet CA-CS/HHF composite beads with different weight ratios of HHF. As can be seen, with a larger proportion of HHF, the spherical beads, with diameters of 3.0 $\mathrm{mm}$, have a more significant black color in the wet state. This appearance change provided further support that CS was embedded with HHF. In marked contrast with the flat surface of neat CS (the inset image of Fig. 2b), the pictured CA-CS/HHF bead was highly rugged with abundant papillae and interstitial spaces (Fig. 2b). Obviously, the flat surface of the CS was destroyed by the introduction of HHF, which has a regular rodlike structure (Fig. 2d). Fig. 2c is the cross section of a CA-CS/ HHF bead; it is obvious that lots of rod-like HHF was implanted into the interior of the pure CS bead, giving further evidence that the internal linkage between HHF and CS provides superior mechanical strength. Moreover, there are also some HHF granules at the outer surface of CA-CS/HHF, indicating that the HHF fillers are immobilized fully by CS beads inside and outside. In analogy, the incorporation of HHF could contribute to improving the mechanical properties of CA-CS/HHF hybrid beads and the unique surface morphology of CA-CS/HHF, with large quantities of carboxylic groups, is favorable for providing sufficient space for protein adsorption.

\subsection{Enhanced mechanical stability of CA-CS/HHF composite beads}

Since favorable mechanical properties can endow protein adsorbents with long service lives and good endurance under high pressure, it is extremely important to improve the mechanical properties of the CA-CS/HHF composite beads by impregnating HHF into the CS matrix. Good mechanical properties have been previously identified as being correlated with the presence of well-distributed fibers or nanomaterials in the chitosan matrix. ${ }^{43}$ Thus, in order to investigate the effect of HHF fillers on the mechanical properties of CA-CS/HHF beads, a series of hybrid beads with various HHF contents $(0-50 \%)$ were studied using compression testing (Fig. 3).

Fig. 3a reveals that the applied force values for CA-CS/HHF hybrid beads were generally higher than those for pure CS beads and presented an apparent increasing trend upon increasing the weight ratio of HHF and CS from 10 to $50 \%$, and these values varied from 0.39 to $0.84 \mathrm{~N}$ with $40 \%$ deformation. Moreover, the variation in the force values between the 40 and $50 \%$ beads was small $(<0.05 \mathrm{~N})$, indicating that $\mathrm{CA}-\mathrm{CS} / \mathrm{HHF}$
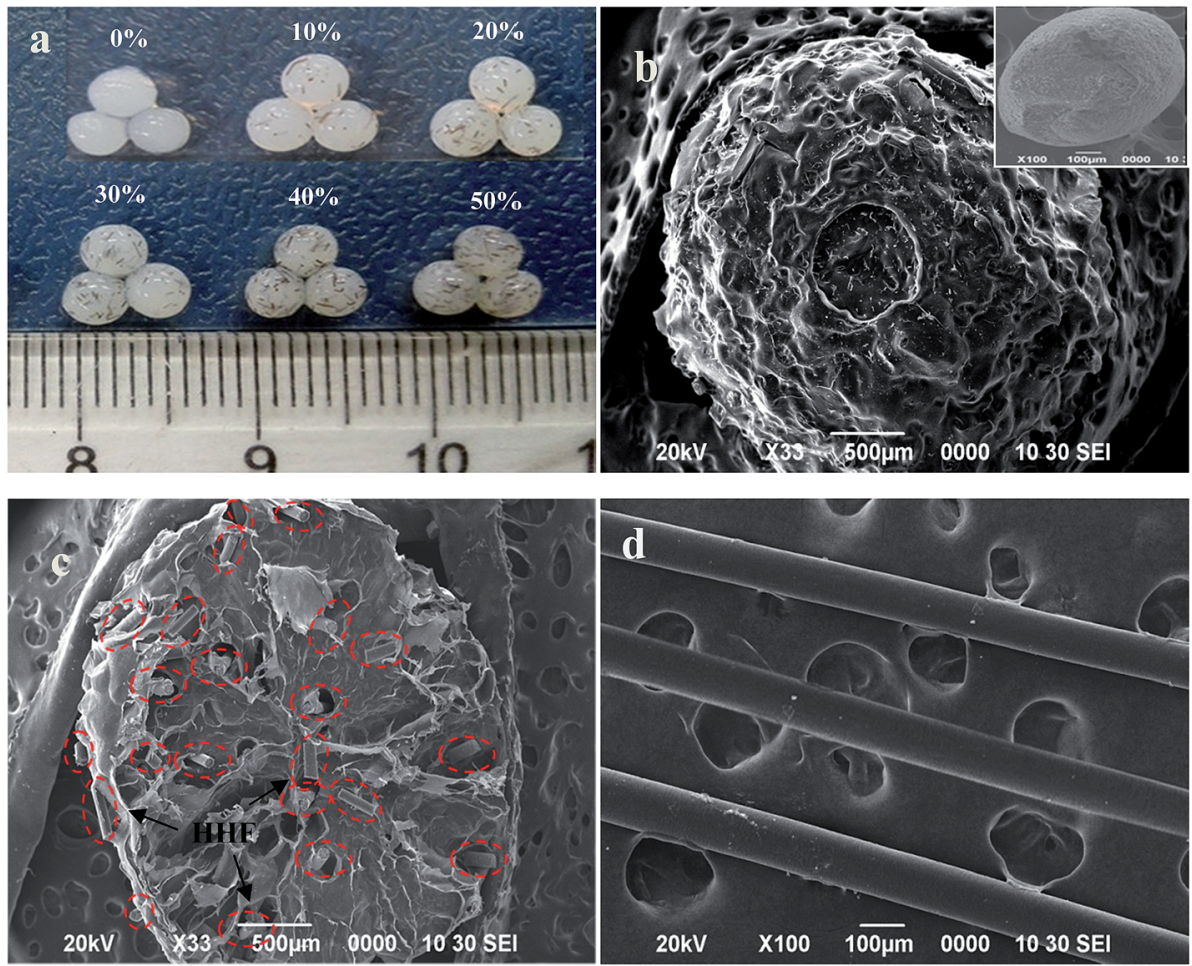

Fig. 2 Appearance of CA-CS/HHF hybrid beads with different HHF content (a), and SEM micrographs of CA-CS/HHF and CS beads (b), the cross section of $\mathrm{CA}-\mathrm{CS} / \mathrm{HHF}(\mathrm{c})$ and $\mathrm{HHF}(\mathrm{d})$. 

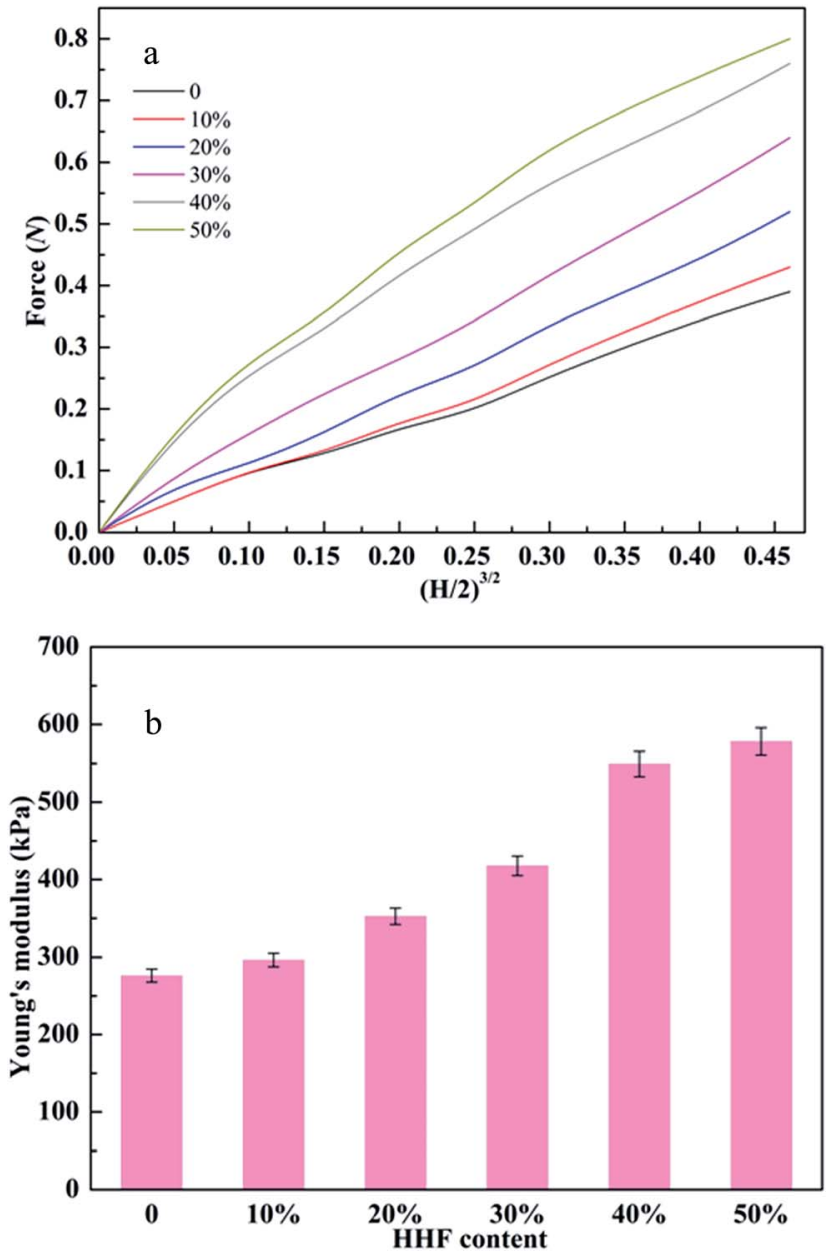

Fig. 3 (a) The force $(\mathrm{N})$ and $(H / 2)^{3 / 2}$ curves of CA-CS/HHF composite beads with $40 \%$ final deformation; $H$ is the displacement. (b) Effect of the HHF content on the Young's modulus of CA-CS/HHF composite beads.

hybrid beads with high mechanical performance can be obtained by the incorporation of $40 \% \mathrm{HHF}$ into the CS matrix. Since the space within the CA-CS/HHF composite beads was occupied by the tough HHF, the composite beads became more rigid compared with the pure CS beads, and consequently beads with a higher feed ratio of HHF fillers required a larger force to produce a given degree of deformation. Additionally, the stiff HHF fillers impeded the movement of the CS chains necessary for shape change under external stress, also resulting in a larger force being required to deform the CA-CS/HHF composite beads. Most importantly, the HHFs dispersed within the hybrid beads could form a string-like matrix owing to their slenderness. Hence, compared to CS beads, the CA-CS/HHF hybrid beads could transfer compression stress more evenly from the soft chitosan matrix phase to the rigid HHF filler, resulting in enhanced mechanical strength. ${ }^{44}$ Hence, the mechanical strength of the CA-CS/HHF hybrid beads can be enhanced by simply impregnating HHF into the CS matrix. Moreover, judging from the relationships between the Young's modulus and HHF content, the Young's moduli of the CA-CS/HHF hybrid beads were significantly higher than that of the control sample (CS beads) and increased with an increasing feeding ratio of HHF (Fig. 3b). Specifically, the Young's moduli of the CA-CS/ HHF beads were $298 \pm 8 \mathrm{kPa}, 352 \pm 10 \mathrm{kPa}, 417 \pm 12 \mathrm{kPa}$, $549 \pm 16 \mathrm{kPa}$, and $578 \pm 17 \mathrm{kPa}$ at ratios of $10 \%, 20 \%, 30 \%, 40 \%$ and $50 \%$, respectively, whereas the corresponding value for neat CS beads was only $276 \pm 8 \mathrm{kPa}$. For comparison, Eng Seng Chan et al. verified that the Young's modulus of alginate beads increased from $430 \pm 5 \mathrm{kPa}$ to $582 \pm 7 \mathrm{kPa}$ after embedding $100 \mathrm{~g} \mathrm{~L}^{-1}$ of halloysite nanotubes. ${ }^{45}$ All of these results indicate that it is more effective to improve the mechanical stability of the CA-CS/HHF hybrid beads by embedding HHF into the CS matrix, and the weight ratio of $40 \%$ was selected to perform the subsequent protein adsorption experiments.

\subsection{Optimizing protein adsorption performance of CA-CS/ HHF composite beads}

The adsorption capability of CA-CS/HHF composite beads is mainly dependent on electrostatic attraction between ionized carboxyl groups on the CA-CS/HHF hybrid beads and the positively charged residues on proteins; that is, the adsorption performance of composite beads can be significantly improved as the amount of carboxyl groups on CA-CS/HHF increases. Thus, it was necessary to determine the number of carboxyl groups introduced on CA-CS/HHF composite beads and to optimize lysozyme adsorption by adjusting the concentration of CA (from 0.1 to $0.6 \mathrm{~mol} \mathrm{~L}^{-1}$ ). The experimental results are depicted in Fig. 4.

As Fig. 4 shows, the carboxyl content of CA-CS/HHF composite beads was dramatically increased in comparison with that of native CS/HHF. Specifically, the carboxyl content increased from 68 meq. $/ 100 \mathrm{~g}$ to 407 meq. $/ 100 \mathrm{~g}$ upon increasing the CA concentration from 0 to $0.4 \mathrm{~mol} \mathrm{~L}^{-1}$, signifying that increasing numbers of $\mathrm{CA}$ molecules were fixed on CA-CS/HHF. Above this CA concentration range, however, the carboxyl content negligibly changed, indicating that $0.4 \mathrm{~mol} \mathrm{~L}^{-1}$ of CA was sufficient to saturate the carboxyl groups on the composite beads. Correspondingly, the adsorption capacities of

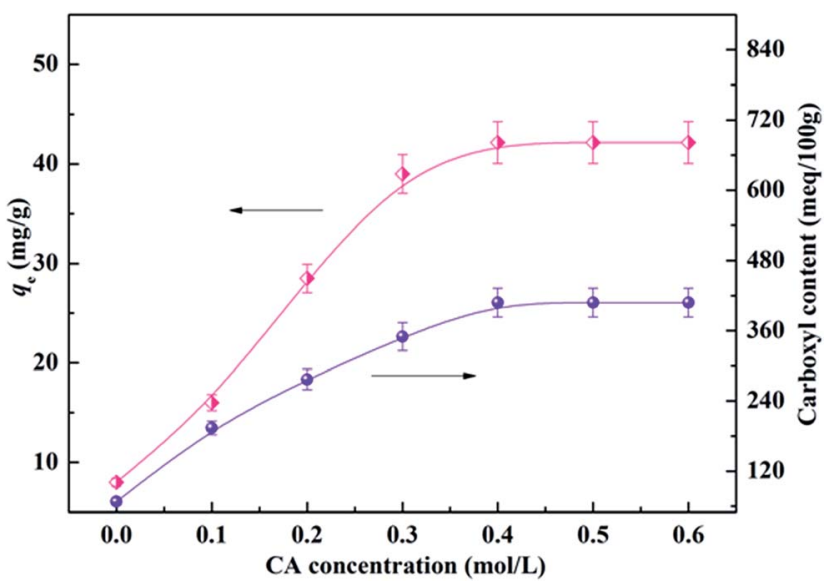

Fig. 4 Effect of the CA concentration on the carboxyl content and adsorption capacity of CA-CS/HHF composite beads. 
the CA-CS/HHF composite beads present a typical sustained increasing trend upon increasing the CA concentration, and the maximum capacity was obtained with a concentration of $0.4 \mathrm{~mol} \mathrm{~L}^{-1}$. A further increase in the CA concentration did not result in an enhancement of the adsorption behavior, demonstrating that the adsorption process had reached an equilibrium state because of the limited number of carboxyl groups on the composite beads' surfaces. It is obvious that the changes in the lysozyme adsorption capacity are consistent with those of the carboxyl group content. Conforming to the maximum lysozyme adsorption capacity, CA-CS/HHF composites modified with $0.4 \mathrm{~mol} \mathrm{~L}^{-1} \mathrm{CA}$ were employed to perform the following experiments.

\subsection{Tunable protein adsorption study of CA-CS/HHF composite beads}

Considering that the electrical charge on the proteins and CA$\mathrm{CS} / \mathrm{HHF}$ composite beads could be tuned by the ionization of acidic or basic groups associated with the proteins and composite, the $\mathrm{pH}$ value of a protein solution plays a critical role in testing the adsorption capacity of charged CA-CS/HHF composite beads. As the solution $\mathrm{pH}$ is changed, the ionized acidic or basic groups contribute to attractive or repulsive interactions between the protein and the composite. ${ }^{\mathbf{4 6 , 4 7}}$ To study the adsorption of protein as a function of the solution $\mathrm{pH}$, positively charged lysozyme (LYZ) was selected as a model protein. The adsorption of LYZ (at a concentration of $1 \mathrm{~g} \mathrm{~L}^{-1}$ ) at different $\mathrm{pH}$ values was performed and the obtained values are illustrated in Fig. 5a.

As can also be seen, LYZ absorption on the samples is low under acidic conditions, but sharply increases and almost reaches equilibrium in the $\mathrm{pH}$ range from 7 to 8 . This phenomenon can be attributed to the abundant carboxyl groups on the surface of the CA-CS/HHF composite beads. In theory, most of the $-\mathrm{COO}^{-}$groups fixed on the structures of the CA-CS/HHF materials could combine with hydrogen ions $\left(\mathrm{H}^{+}\right)$in acidic media to form $-\mathrm{COOH}$ groups, decreasing the negative surface charges of the samples. With the reduction of the $-\mathrm{COO}^{-}$ groups, the electrostatic force between the positively charged LYZ (LYZ ${ }^{+}$) and anionic groups would be weakened; consequently, the adsorption capacity was limited. The electrostatic attraction between lysozyme and $\mathrm{CA}-\mathrm{CS} / \mathrm{HHF}$ strengthened when the $\mathrm{pH}$ value was increased, since the number of negatively charged $-\mathrm{COO}^{-}$groups increased, promoting the binding of more LYZ onto the CA-CS/HHF composite beads. When the LYZ solution $\mathrm{pH}$ was higher than 8 , the observed adsorption of LYZ on the CA-CS/HHF composite beads gradually reduced. This phenomenon can be understood considering the fact that a positively charged self rejecting layer of LYZ molecules was formed on the CA-CS/HHF surface via electrostatic attraction between the positively charged LYZ $\left(\mathrm{LYZ}^{+}\right)$and the negatively charged composite surface. ${ }^{48,49}$ Long range exclusion, by a positively charged self rejecting layer of LYZ, of similarly charged LYZ molecules in solution could be responsible for the further decline in the adsorption capacity. Therefore, the CA$\mathrm{CS} / \mathrm{HHF}$ composite beads could be used to realize the
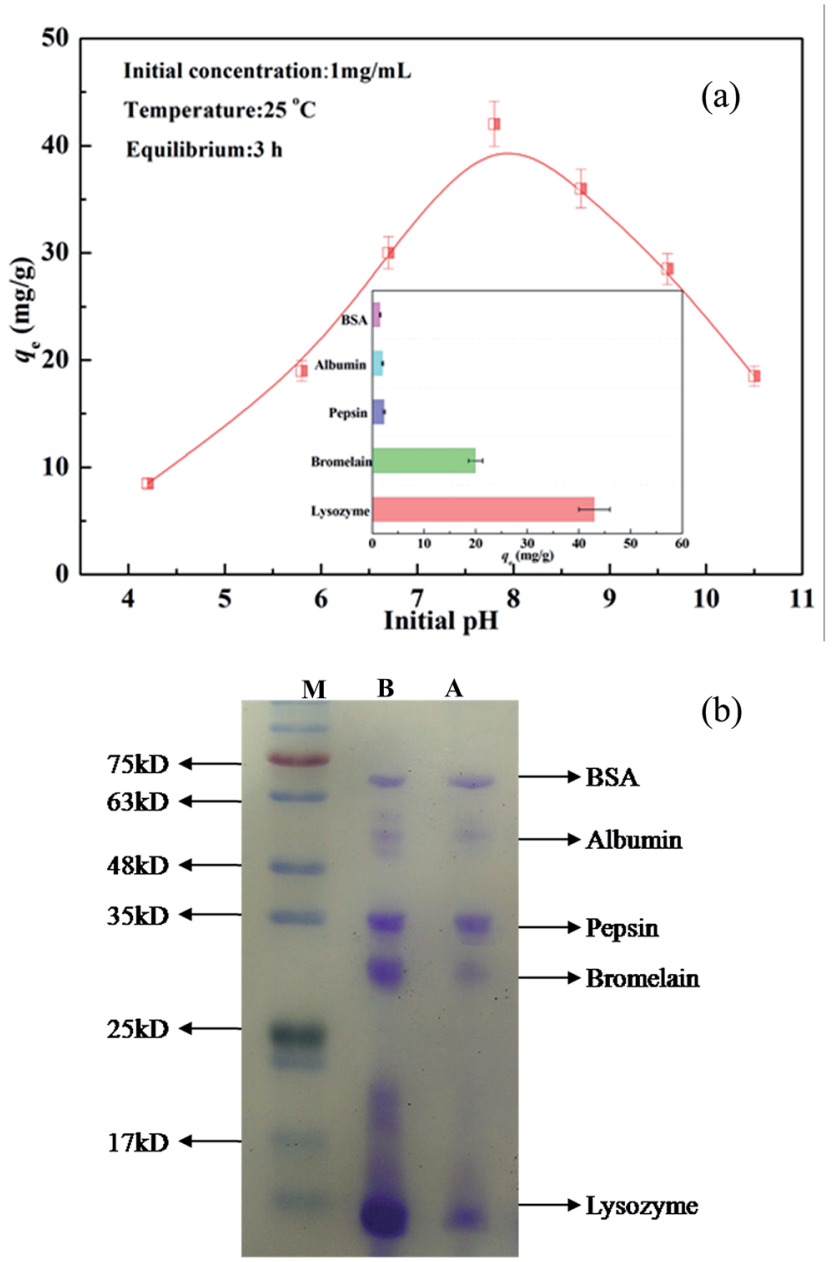

(b)

Fig. 5 (a) The observed adsorption of LYZ (1 mg mL $\left.{ }^{-1}\right)$ onto CA-CS/ HHF composite beads. Inset image: adsorption capacities toward different types of separate proteins. (b) SDS-PAGE analysis of the purification of a protein mixture: $M$, protein marker; lanes $B$ and A, protein mixture before and after adsorption on CA-CS/HHF hybrid beads.

selective adsorption of positively charged proteins by regulating and controlling the buffer $\mathrm{pH}$ values. Given that protein solutions with near neutral $\mathrm{pH}$ values are more stable and more appropriate in practical applications, a $\mathrm{pH}$ value of 7.8 was selected to conduct the subsequent tests.

From the inset image in Fig. 5a, it is apparent that the adsorption of positively charged proteins (LYZ, bromelain) was much greater when compared to that of other proteins (BSA, albumin, pepsin), and this result is connected with the surface charge characteristics of the experimental subject. The composites' adsorption of positively charged proteins was mainly controlled by electrostatic forces between the positive charges on the LYZ and bromelain and the negative charge on the composite, and therefore they are attracted each other, ${ }^{50}$ indicating that more positively charged proteins than negatively charged molecules can make contact with a composite with the same surface area. Hence, the variation in the adsorption capacity towards differently charged proteins suggests that the 
resultant materials can be a potential candidate for the easy adsorption of positively charged proteins. Moreover, the adsorption ability of the obtained CA-CS/HHF composite beads toward a protein mixture was also assessed at a buffer $\mathrm{pH}$ of 7.8, as visually illustrated in Fig. 5b. Apparently, the bands for lysozyme and bromelain presented color fading after their adsorption by the CA-CS/HHF composite beads. Conversely, the change of the band colors for BSA, albumin, and pepsin can be hardly observed, since the proteins have the same surface charges as the carboxyl groups on the CA-CS/HHF composite beads. Accordingly, the CA-CS/HHF composite beads could be used an intriguing tool for the adsorption of positively charged proteins by adjusting and controlling the $\mathrm{pH}$ of a protein mixture.

\subsection{Adsorption kinetics}

Fast adsorption kinetics are one of most crucial factors for protein adsorbents since they have a direct influence on the actual efficiency of the adsorbents. The existence of citric acid molecules on the surfaces of the CA-CS/HHF composite beads improves the binding capacity towards positively charged lysozyme, which can be verified by comparing the adsorption capacities of CA-CS/HHF and CS/HHF beads. Therefore, the adsorption kinetics performances of CA-CS/HHF and CS/HHF composite beads were investigated by the determination of the residence time needed for the completion of the lysozyme adsorption process, as shown in Fig. 6. It can be easily observed that the adsorption by CA-CS/HHF abruptly increased during the initial stage and the increasing trend did not stop until a state of equilibrium was achieved after approximately $3 \mathrm{~h}$, indicating the high adsorption efficiency of CA-CS/HHF for lysozyme molecules. Furthermore the adsorption capacity of CA-CS/HHF composite beads is up to $42.1 \mathrm{mg} \mathrm{g}^{-1}$ while the CS/ HHF beads without citric acid decoration have a lower binding capacity $\left(7.9 \mathrm{mg} \mathrm{g}^{-1}\right)$. The enhanced adsorption capacity is attributed to the considerable availability of carboxyl groups derived from the citric acid layer on the CA-CS/HHF composite bead's surface, which provides numerous external adsorption sites for effectively binding lysozyme molecules through the electrostatic attraction between anionic CA-CS/HHF and cationic lysozyme. ${ }^{51}$

Kinetics is one of the most fascinating characteristics responsible for the efficiency of absorption. Significantly, the experimental data at $25{ }^{\circ} \mathrm{C}$ were fitted by pseudo-first-order and pseudo-second-order kinetic models, as shown in Fig. 6. These two kinetic models were defined by the following formulas: ${ }^{52,53}$

$$
\begin{gathered}
\ln \left(q_{\mathrm{e}}-q_{t}\right)=\ln q_{\mathrm{e}}-k_{1} t \\
\frac{t}{q_{t}}=\frac{1}{k_{2} q_{\mathrm{e}}^{2}}+\frac{t}{q_{\mathrm{e}}}
\end{gathered}
$$

where $q_{\mathrm{e}}$ and $q_{t}\left(\mathrm{mg} \mathrm{g}^{-1}\right)$ represent the adsorption capacities at equilibrium and at any time $(\mathrm{min})$, respectively. $k_{1}\left(\mathrm{~min}^{-1}\right)$ and $k_{2}\left(\mathrm{~g} \mathrm{~g}^{-1} \min ^{-1}\right)$ are the rate constants and can be evaluated from the intercepts and slopes of linear plots of $\ln \left(q_{\mathrm{e}}-q_{t}\right)$ versus $t$ and $t / q_{t}$ versus $t$, respectively. The corresponding kinetic parameters including $k_{1}, k_{2}$, correlation coefficients $\left(R^{2}\right)$, and
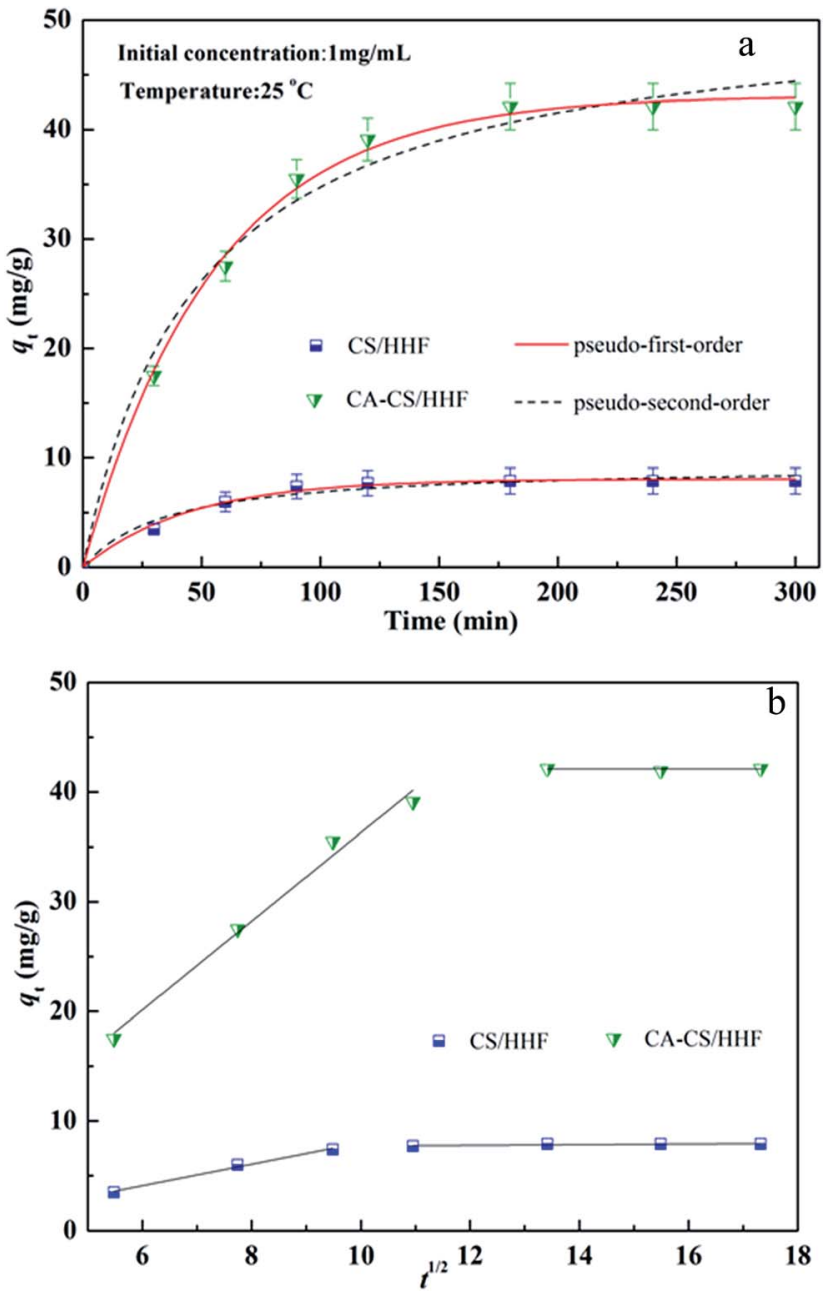

Fig. 6 (a) Adsorption kinetics of both $\mathrm{CS} / \mathrm{HHF}$ and $\mathrm{CA}-\mathrm{CS} / \mathrm{HHF}$ samples in $1 \mathrm{mg} \mathrm{mL}^{-1}$ lysozyme solution; (b) intraparticle diffusion plots.

calculated $q_{\mathrm{e}, \mathrm{cal}}$ values are determined by a non-linear fitting method, as tabulated in Table 1. For the CS/HHF and CA-CS/ HHF samples, the $R^{2}$ values for the pseudo-first-order model

Table 1 The kinetic parameters and coefficients of LYZ adsorption onto $\mathrm{CS} / \mathrm{HHF}$ and $\mathrm{CA}-\mathrm{CS} / \mathrm{HHF}$ composite beads

\begin{tabular}{llll}
\hline & & \multicolumn{2}{l}{ Samples } \\
\cline { 4 - 4 } Kinetics type & Kinetic constant & CS/HHF & CA-CS/HHF \\
\hline \multirow{2}{*}{ Pseudo-first-order } & $q_{\mathrm{e}, \exp }\left(\mathrm{g} \mathrm{g}^{-1}\right)$ & 7.91 & 42.10 \\
& $q_{\mathrm{e}, \mathrm{cal}}\left(\mathrm{g} \mathrm{g}^{-1}\right)$ & 8.077 & 43.10 \\
& $k_{1}\left(\mathrm{~min}^{-1}\right)$ & 0.022 & 0.018 \\
& $R^{2}$ & 0.9911 & 0.9969 \\
Pseudo-second-order & $\chi^{2}$ & 0.073 & 0.7096 \\
& $q_{\mathrm{e}, \mathrm{cal}}\left(\mathrm{g} \mathrm{g}^{-1}\right)$ & 9.38 & 51.59 \\
& $k_{2}\left(\mathrm{~g} \mathrm{~g}^{-1} \mathrm{~min}^{-1}\right)$ & 0.0029 & 0.004 \\
& $R^{2}$ & 0.9829 & 0.9672 \\
Intraparticle diffusion & $\chi^{2}$ & 3.929 & 0.2708 \\
& $K_{\mathrm{id}, 1}$ & 0.9791 & 4.041 \\
& $K_{\mathrm{id}, 2}$ & 0.0297 & 0.012 \\
& $C$ & 7.426 & 42.11 \\
& $R^{2}$ & 0.9831 & 0.9854 \\
& $\chi^{2}$ & 3.082 & 0.9297
\end{tabular}


(0.9911 and 0.9969 , respectively) are obviously higher than those for the pseudo-second-order model (0.9829 and 0.9672, respectively). Additionally, the theoretical values $\left(q_{\text {e,cal }}\right)$ obtained from the pseudo-second-order model seemed to be clearly higher than the experimentally observed data $\left(q_{\mathrm{e}, \exp }\right)$, whereas the values from the pseudo-first-order kinetic model were quite consistent with the experimental values. This signifies that the swelling process could best be described by the pseudo-first-order model.

The steps of the adsorption process are analyzed thoroughly with an intraparticle diffusion model which is represented in eqn (6). ${ }^{54}$

$$
q_{t}=K_{\mathrm{id}} t^{1 / 2}+C
$$

where $k_{\mathrm{id}}\left(\mathrm{mg} \mathrm{g}^{-1} \min ^{-1 / 2}\right)$ is the intraparticle diffusion rate constant and $C\left(\mathrm{mg} \mathrm{g}^{-1}\right)$ is the intercept. The values of the characteristic constants $k_{\text {id }}$ and $C$ were obtained from the slope and intercept, respectively, of a plot of $q_{t}$ versus $t^{1 / 2}$, and the results are displayed in Fig. $6 \mathrm{~b}$ and Table 1 . In the present case, for $\mathrm{CS} / \mathrm{HHF}$ and $\mathrm{CA}-\mathrm{CS} / \mathrm{HHF}$, the data points are related by two straight lines during the LYZ adsorption process. The first one represents the immediate occupation of the most readily available adsorption sites on the surfaces of the CA-CS/HHF composite beads. The second adsorption step may be attributed to very slow diffusion of the protein from the external surfaces into the inner pores. Furthermore, a fit of $q_{t}$ versus $t^{1 / 2}$ is found to be linear, but the plots have nonzero intercepts. This phenomenon indicates that the adsorption process may be of a complex nature involving both surface adsorption and intraparticle diffusion, but that these are not the only controlling factors in determining the kinetics of the process. ${ }^{55,56}$

\subsection{Adsorption isotherms}

Adsorption isotherms are important for describing the adsorption behavior and are also important for providing information about the surface properties of the adsorbent and the design of adsorption systems. Here, commonly employed models including the Langmuir, Freundlich and Temkin isotherm models were developed to test the adsorption data. These models can be described in nonlinear form as follows: ${ }^{57-59}$

Langmuir isotherm:

$$
q_{\mathrm{e}}=\frac{q_{\mathrm{m}} C_{\mathrm{e}} K_{\mathrm{L}}}{1+C_{\mathrm{e}} K_{\mathrm{L}}}
$$

Freundlich isotherm:

$$
q_{\mathrm{e}}=K_{\mathrm{F}} C_{\mathrm{e}}^{1 / n}
$$

Temkin isotherm:

$$
q_{\mathrm{e}}=A \ln K_{\mathrm{T}} C_{\mathrm{e}}
$$

where $q_{\mathrm{e}}$ and $q_{\mathrm{m}}$ represent the equilibrium and theoretical maximum adsorption amounts $\left(\mathrm{mg}^{-1}\right)$, respectively, and $C_{\mathrm{e}}$ is the equilibrium dye concentration $\left(\mathrm{mg} \mathrm{mL}^{-1}\right) . K_{\mathrm{L}}, K_{\mathrm{F}}$ and $K_{\mathrm{T}}$ refer to the constants of the Langmuir, Freundlich and Temkin models, respectively. The parameters $n$ and $A$ are the Freundlich and Temkin coefficients related to the adsorption intensity and surface heterogeneity of the adsorbent, respectively. The values of the parameters as well as the regression coefficients $\left(R^{2}\right)$ can be determined from the above three isotherm equations and are displayed in Table 2 . The $R^{2}$ value $(0.9872)$ for the Langmuir model is much larger than those for the Freundlich model (0.9465) and the Temkin model (0.9741), reflecting that the adsorption process better fits the Langmuir model, and that the adsorption of lysozyme molecules on the CA-CS/HHF adsorbent took the form of monolayer adsorption due to the existence of strong electrostatic attractions between the carboxylic ion groups of the adsorbent and the lysozyme molecules. This result can be further reinforced by the comparison of the experimental points and fitted isotherm plots in Fig. 7.

To evaluate the feasibility of adsorption on the adsorbent, a separation factor known as the equilibrium parameter $\left(R_{\mathrm{L}}\right)$ can be calculated by means of the Langmuir constant, $K_{\mathrm{L}}$ :

$$
R_{\mathrm{L}}=\frac{1}{1+C_{0} K_{\mathrm{L}}}
$$

where $C_{0}$ is the initial lysozyme concentration $\left(\mathrm{mg} \mathrm{L}^{-1}\right)$. The values of $R_{\mathrm{L}}$ give information about the Langmuir adsorption process, be it irreversible $\left(R_{\mathrm{L}}=0\right)$, linear $\left(R_{\mathrm{L}}=1\right)$, favorable $(0<$ $\left.R_{\mathrm{L}}<1\right)$ or unfavorable $\left(R_{\mathrm{L}}>1\right) \cdot{ }^{6,61} R_{\mathrm{L}}$ values for the adsorption of lysozyme are in the range of $0.223-0.801$, at $298.15 \mathrm{~K}$. This confirms that the lysozyme sorption onto CA-CS/HHF is favorable and therefore CA-CS/HHF can be referred to as a proper adsorbent for protein separation.

\subsection{Reversibility of the CA-CS/HHF composite}

From the perspective of economic plausibility, regeneration is an environmentally acceptable option which may be critical to decreasing process costs and providing the possibility of recovering the protein adsorbed from the solution. Generally, it is highly challenging but desirable to preserve the high adsorption capacity of such adsorption systems after repeating many cycles of adsorption and regeneration. Very recently, Ma and his colleagues described a $\mathrm{NaCl}$ treatment procedure for the regeneration of maleic anhydride-functionalized materials. ${ }^{62}$ The authors found that proteins could be directly

Table 2 Adsorption isotherm parameters for $L Y Z$ adsorption at $25^{\circ} \mathrm{C}$

\begin{tabular}{lll}
\hline Models & Model parameters & $R^{2}$ \\
\hline Langmuir isotherm & $q_{\max }=56.12 \mathrm{mg} \mathrm{g}^{-1}$ & 0.9872 \\
& $K_{\mathrm{L}}=2.484 \mathrm{~L} \mathrm{~g}^{-1}$ & \\
& $R_{\mathrm{L}}=0.223-0.801$ & \\
& $\chi^{2}=3.054$ & 0.9465 \\
Freundlich isotherm & $n=2.416$ & \\
& $K_{\mathrm{F}}=39.00 \mathrm{~L} \mathrm{~g}^{-1}$ & \\
Temkin isotherm & $\chi^{2}=10.35$ & \\
& $A=13.34$ & \\
& $K_{\mathrm{T}}=19.69 \mathrm{~L} \mathrm{~g}^{-1}$ & \\
& $\chi^{2}=3.783$ &
\end{tabular}




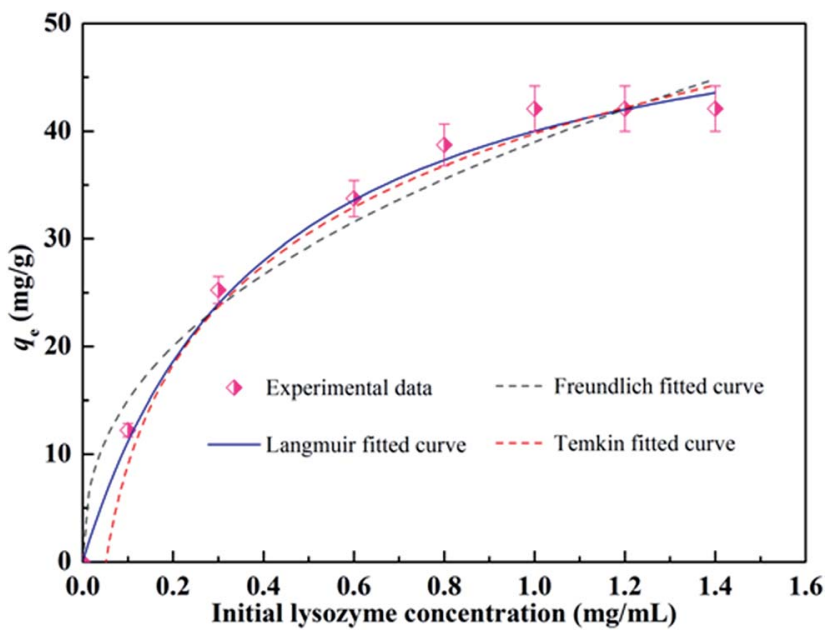

Fig. 7 Isotherm plots for the adsorption of LYZ onto CA-CS/HHF composite beads at $25^{\circ} \mathrm{C}$.

eluted from the carbonyl group functionalized membranes, without the need for any other chemical reagents. Following a similar procedure, a $\mathrm{NaCl}$ solution was employed to elute the adsorbed lysozyme and facilitate the regeneration of the CA$\mathrm{CS} / \mathrm{HHF}$ composite for another cycle of adsorption. The adsorption capacity of the regenerated CA-CS/HHF is shown in Fig. 8.

As shown in Fig. 8, the adsorption capacity of the CA-CS/HHF composite beads was found to decline from $42.1 \mathrm{mg} \mathrm{g}^{-1}$ to $38.4 \mathrm{mg} \mathrm{g}^{-1}$ during 10 regeneration/reuse cycles, suggesting the significant chemical removal of binding lysozyme and the formation of activated CA-CS/HHF composite beads. Upon increasing the number of reuse cycles up to 10 , no prominent difference in the lysozyme-absorbing ability could be observed between any pair of cycles, confirming that the CA-CS/HHF composite beads still retained a high adsorption activity toward lysozyme and can be effectively regenerated and

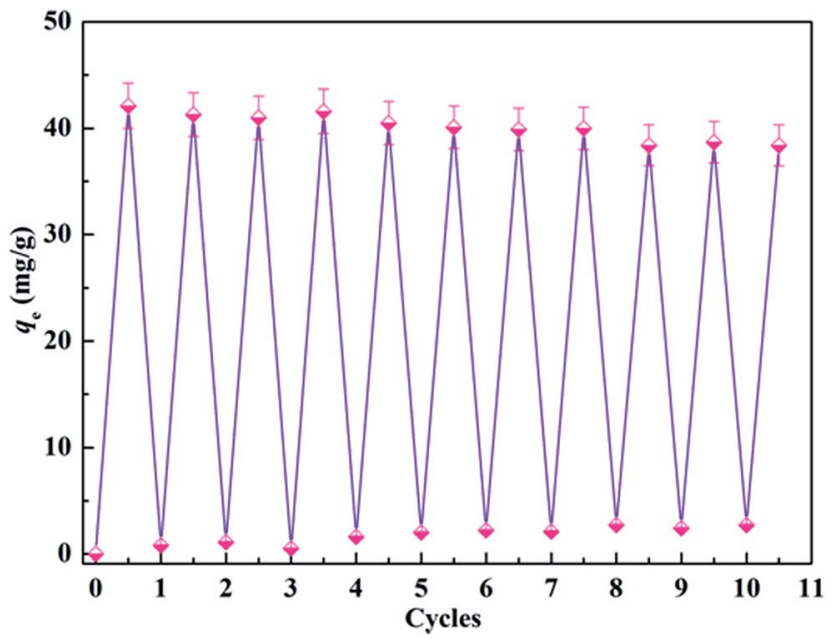

Fig. 8 Change in the adsorption capacity of CA-CS/HHF materials upon increasing the cycle number up to 10 . successively reused. Two major advantages of the CA-CS/HHF composite beads can explain this good reversibility. First, the robust and strong HHF fillers enhance the mechanical stability of the CA-CS/HHF composite beads, avoiding severe fracture during the adsorption-desorption process, and thus effectively prevent the CA molecules from shedding upon regeneration. Second, the large number of active functional groups $(\mathrm{COOH})$ inherited from CA are not destroyed and are preserved after rinsing with natural salt solution repeatedly, endowing the regenerated composite with good adsorption performance. The excellent reversibility of the CA-CS/HHF composite beads can, significantly, achieve the demands of long service life for their practical application.

\section{Conclusion}

In conclusion, the present research was focused on developing a facile and eco-friendly strategy for the fabrication of novel carboxyl group functionalized composite beads (CA-CS/HHF) via the thermo-chemical modification of encapsulated coated human hair fiber (HHF) with citric acid. HHF and citric acid were introduced into the formulations as a reinforcing filler and protein catcher, respectively. SEM and FTIR analyses confirmed that HHF fillers were implanted into the interior of the chitosan beads and that abundant carboxylic groups derived from the citric acid are immobilized on the outer surface of CA-CS/HHF. The mechanical tests showed that the impregnation of HHF into the chitosan matrix with various weight ratios could effectively enhance the mechanical stability of the CA-CS/HHF composite beads in comparison with pure chitosan beads. The sodium dodecyl sulfate polyacrylamide gel electrophoresis method was used to test the adsorption of positively charged proteins. The obtained CA-CS/HHF exhibited a high lysozyme adsorption capacity of $42.1 \mathrm{mg} \mathrm{g}^{-1}$ within $3 \mathrm{~h}$, and the adsorption behavior followed pseudo-first-order kinetics and a Langmuir model. Most importantly, the CA-CS/HHF composites possessed good reversibility after 10 regeneration/ reuse cycles and the adsorption capacity was found to have declined to $38.4 \mathrm{mg} \mathrm{g}^{-1}$. The fast adsorption equilibrium, high adsorption capacity and retention properties, as well as good reversibility, attained by these CA-CS/HHF composite beads would be fruitful for guiding future design of a composite for lysozyme adsorption.

\section{Conflict of interest}

The authors declare no competing financial interest.

\section{Acknowledgements}

This work was supported by the Shaanxi Provincial Natural Science Foundation of China (No. 2015JM2071), the National Natural Science Foundation of China (No. 21176031) and Fundamental Research Funds for the Central Universities (No. 310829162014, No. 310829161015, No. 310829175001). 


\section{References}

1 S. Volden, K. Zhu, B. Nystrom and W. R. Glomm, Colloids Surf., B, 2009, 72, 266-271.

2 Y. Li, T. Y. Lin, Y. Luo, Q. Liu, W. Xiao, W. Guo, D. Lac, H. Zhang, C. Feng, S. Wachsmann-Hogiu, J. H. Walton, S. R. Cherry, D. J. Rowland, D. Kukis, C. Pan and K. S. Lam, Nat. Commun., 2014, 5, 4712.

3 B. Li, B. Jiang, B. M. Boyce and B. A. Lindsey, Biomaterials, 2009, 30, 2552-2558.

4 L. J. M. Rao, Int. J. Food Sci. Technol., 2009, 4, 1464-1466.

5 J. Li, X. Liao, Q. Zhang and B. Shi, J. Chromatogr. B: Anal. Technol. Biomed. Life Sci., 2013, 928, 131-138.

6 S. Kumar, V. K. Aswal and P. Callow, Langmuir, 2014, 3, 15881598.

7 W. Peng, J. Mater. Chem. B, 2013, 1, 3506-3512.

8 S. C. Smith, F. Ahmed, K. M. Gutierrez and D. F. Rodrigues, Chem. Eng. J., 2014, 240, 147-154.

9 D. O'Dell, X. Serey, P. Kang and D. Erickson, Sci. Rep., 2014, 4, 6707.

10 R. S. Prakasham, D. G. Sarala, K. R. Laxmi and C. S. Rao, J. Phys. Chem. C, 2007, 111, 3842-3847.

11 A. J. Varma, S. V. Deshpande and J. F. Kennedy, Carbohydr. Polym., 2004, 55, 77-93.

12 W. S. Adriano, D. B. Mendonca, D. S. Rodrigues, E. J. Mammarella and R. L. C. Giordano, Biomacromolecules, 2008, 9, 2170-2179.

13 M. Qiu, C. Wu, G. R. Ren, X. L. Liang, X. Y. Wang and J. Y. Huang, Food Chem., 2014, 155, 105-111.

14 J. Lee, S. Ko and H. Kwon, Toxicol. Lett., 2010, 196, S275.

15 S. H. Chang and C. H. Chian, Appl. Surf. Sci., 2013, 282, 735740.

16 L. Y. Wang, G. H. Ma and Z. G. Su, J. Controlled Release, 2005, 106, 62-75.

17 N. Ye, Y. Xie, P. Shi, T. Gao and J. Ma, Mater. Sci. Eng., C, 2014, 45, 8-14.

18 Y. L. Liu, Y. F. Chen, S. P. Wen, C. C. Ren, P. Y. Cao, J. F. Huang, B. Liu and G. B. Jiang, J. Dispersion Sci. Technol., 2015, 37, 1104-1114.

19 V. N. Tirtom, A. Dinçer, S. Becerik, T. Aydemir and A. Çelik, Chem. Eng. J., 2012, 197, 379-386.

20 Y. Zhou, S. Fu, L. Zhang, H. Zhan and M. V. Levit, Carbohydr. Polym., 2014, 101, 75-82.

21 F. Mirahmadi, M. Tafazzoli-Shadpour, M. A. Shokrgozar and S. Bonakdar, Mater. Sci. Eng. C Mater. Biol. Appl., 2013, 334, 786-794.

22 M. L. Hassan, S. M. Fadel, N. A. El-Wakil and K. Oksman, J. Appl. Polym. Sci., 2012, 23, 2938.

23 Z. Wang, Q. Hu, X. Dai, H. Wu, Y. Wang and J. Shen, Polym. Compos., 2009, 30, 1517-1522.

24 T. U. Xian-Yu, L. Gao, D. M. Deng, Y. X. Zhang and A. G. Zhu, J. Jianghan Pet. Inst., 2005, 4, 333-335.

25 A. Gupta, J. Waste Manage., 2014, 2014, 1-18.

26 M. Brebu and I. Spiridon, J. Anal. Appl. Pyrolysis, 2011, 91, 288-295.
27 R. C. D. Guzman, M. R. Merrill, J. R. Richter, R. I. Hamzi and O. K. Greengauz-Roberts, Biomaterials, 2011, 32, 8205-8217.

28 S. A. Yaseen, Journal of Engineering \& Technology, 2013, 31, 1870-1881.

29 G. Bayramoğlu, G. Ekici, N. Beşirli and M. Y. Arica, Colloids Surf., A, 2007, 310, 68-77.

30 W. Hua, Y. Lou, W. Xu, Z. Cheng and X. Gong, Appl. Microbiol. Biotechnol., 2015, 100, 1-13.

31 J. Sun, S. Rao, Y. Su, R. Xu and Y. Yang, Colloids Surf., A, 2011, 389, 97-103.

32 D. S. Franklin and S. Guhanathan, Polym. Bull., 2014, 71, 93110.

33 Q. Fu, X. Wang, Y. Si, L. Liu, J. Yu and B. Ding, ACS Appl. Mater. Interfaces, 2016, 8, 11819-11829.

34 W. Zhang, G. Li, Y. Fang and X. Wang, J. Membr. Sci., 2007, 295, 130-138.

$35 \mathrm{H}$. Hertz, Journal für die reine und angewandte Mathematik, 1881, 92, 156-171.

36 H. Kaygusuz, G. A. Evingür, P. Önder, R. V. Klitzing and F. B. Erim, Int. J. Biol. Macromol., 2016, 92, 220-224.

37 A. Salam, J. J. Pawlak, R. A. Venditti and K. El-Tahlawy, Cellulose, 2011, 18, 1033-1041.

38 S. Sun, Y. Tang, Q. Fu, X. Liu, L. Guo, Y. Zhao and C. Chang, Int. J. Biol. Macromol., 2012, 50, 1002-1007.

39 C. Demitri, R. Del Sole, F. Scalera, A. Sannino, G. Vasapollo, A. Maffezzoli, L. Ambrosio and L. Nicolais, J. Appl. Polym. Sci., 2008, 110, 2453-2460.

40 M. Wang, T. Zhao, G. Wang and J. Zhou, Text. Res. J., 2014, 84, 1315-1324.

41 B. S. Chiou, H. Jafri, T. Cao, G. H. Robertson, K. S. Gregorski, S. H. Imam, G. Glenn and W. J. Orts, J. Appl. Polym. Sci., 2013, 129, 3192-3197.

42 Y. Zhou, S. Fu, L. Zhang and H. Zhan, Carbohydr. Polym., 2013, 97, 429-435.

43 S. Chatterjee, W. L. Min and S. H. Woo, Carbon, 2009, 47, 2933-2936.

44 J. N. Coleman, U. Khan, W. J. Blau and Y. K. Gun'ko, Carbon, 2006, 44, 1624-1652.

45 C. S. C. Chiew, P. E. Poh, P. Pasbakhsh, B. T. Tey, H. K. Yeoh and E. S. Chan, Appl. Clay Sci., 2014, 101, 444-454.

46 H. T. Chiu, J. M. Lin, T. H. Cheng, S. Y. Chou and C. C. Huang, J. Appl. Polym. Sci., 2012, 125, 616-621.

47 G. Baier, C. Costa, A. Zeller, D. Baumann, C. Sayer, P. H. H. Araujo, V. Mailänder, A. Musyanovych and K. Landfester, Macromol. Biosci., 2011, 11, 628-638.

48 V. Valino, M. F. S. Roman, R. Ibanez and I. Ortiz, Sep. Purif. Technol., 2014, 125, 163-169.

49 M. Kumar and M. Ulbricht, RSC Adv., 2013, 3, 12190-12203.

50 H. Y. Huang, T. J. Lo, Y. C. Chen, J. B. Hu and P. L. Urban, Anal. Methods, 2013, 5, 5908-5911.

51 R. Gong, K. Zhong, Y. Hu, J. Chen and G. Zhu, J. Environ. Manage., 2008, 88, 875-880.

52 M. Evren, I. Acar, K. Guclu and G. Guclu, Can. J. Chem. Eng., 2014, 92, 52-59.

53 T. Singh and R. Singhal, J. Appl. Polym. Sci., 2013, 129, 31263139. 
54 M. Ghaedi, F. Karimi, B. Barazesh, R. Sahraei and A. Daneshfar, J. Ind. Eng. Chem., 2013, 19, 756-763.

55 V. Vadivelan and K. V. Kumar, J. Colloid Interface Sci., 2005, 286, 90-100.

56 D. K. Mahmoud, M. A. M. Salleh, W. A. W. A. Karim, A. Idris and Z. Z. Abidin, Chem. Eng. J., 2012, 181-182, 449-457.

57 I. Langmuir, J. Am. Chem. Soc., 1916, 38, 2221-2295.

58 H. M. F. Freundlich, J. Phys. Chem., 1906, 57, 385-470.
59 J. Chatterjee, N. Rai and S. K. Sar, Orient. J. Chem., 2014, 30, 775-784.

60 K. R. Hall, L. C. Eagleton, A. Acrivos and T. Vermeulen, Ind. Eng. Chem. Fundam., 1966, 5, 212-223.

61 Y. Yang, G. Wang, B. Wang, Z. Li, X. Jia, Q. Zhou and Y. Zhao, Bioresour. Technol., 2011, 102, 828-834.

62 J. Ma, X. Wang, Q. Fu, Y. Si, J. Yu and B. Ding, ACS Appl. Mater. Interfaces, 2015, 7, 15658-15666. 